\title{
ZnO Nanocomposite Membranes for Desalination
}

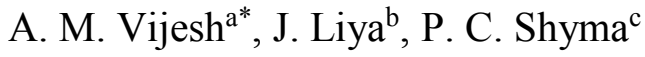

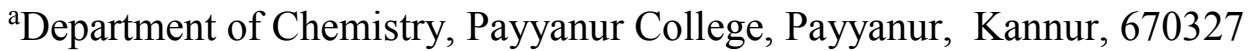 \\ Kerala, India \\ ${ }^{b}$ Department of Physics, Payyanur College, Payyanur, Kannur, 670327 Kerala, India \\ ${ }^{\mathrm{c} S e Q u e n t ~ S c i e n t i f i c ~ L t d, ~ N o . ~} 120$ A\&B, Industrial Area, Baikampady, 575014 \\ Mangalore, India
}

\begin{abstract}
Severe drinking water scarcity is a major problem around the world and pressure driven membrane processes are gaining importance in the field of water purification. This work mainly focuses on improving membrane performance in terms of hydrophilicity, solute rejection, etc. It emphasizes on the preparation of polysulfone (PSf) based blend membranes via phase inversion method. PSf membrane is modified by the addition of zinc oxide $(\mathrm{ZnO})$ nanoparticle at various compositions and the resultant membrane performances were studied. The PSf-ZnO membranes were characterized by ATR-IR and SEM. These membranes showed much better salt rejection performance.
\end{abstract}

Keywords: ZnO Nanoparticles, PSf membrane, desalination, blend, nanofiltration

\subsection{INTRODUCTION}

The shortage of pure drinking water is increasing every day due to human activities. Inorder to overcome this one has to find out a suitable process for water purification. Among the various methods of water purification, membrane filtration is more attractive due to its simplicity, relatively high effiency and low cost [1]. Hydrophilicity, porous structure, antifouling property and chemical resistance of the feed solution are the key membrane characteristics that influence the performance of the membrane separation.

Polysulfone (PSf) is a common polymer for the manufacturing of memberanes due to its chemical stability and thermal resistance [2]. There are many research is taking place around the world to increase its mechanical properties. PSf based composite membranes are extensively used in various separation techniques [3]. But, hydrophobic nature of PSf polymer limits its use as a membrane material for desalination purpose [4]. Diverse methodologies have been developed by many researchers to enhance its hydrophilic character such as, chemical surface treatment and the addition of hydrophilic additives [5].

Addition of nano particle is one of the recent development in the membrane technology, which improves the performances of the membranes filtration [6-8]. The water permeability of the psf membranes was enhanced under high pressure in reverse osmosis (RO) [9-11]. Thus, in this work, being a beginner in the field of membrane research, we mixed zinc oxide $(\mathrm{ZnO})$ nanoparticles with PSf in various compositions hoping that it will increase the hydrophilic nature of the synthesized composite membranes. Membranes were synthesized via phase inversion method and its 
characterization was performed. The salt rejection performance was studied by using electrolyte solution of $\mathrm{NaCl}$. Results of such studies were discussed in this paper.

\subsection{METHODS}

\subsection{Materials}

Low molecular weight PSf with molecular weight $35,000 \mathrm{~g} / \mathrm{mol}$ was purchased from the Sigma Aldrich Company. 1-methyl-2-pyrrolidone (NMP) was purchased from Merk India, Ltd. Commercially available $\mathrm{ZnO}$ nano powder (Sigma Aldrich) were used for the membrane preparation. $\mathrm{NaCl}$ was used as feed solutions for rejection studies.

\subsection{Synthesis of Polysulfone membrane}

PSf ( $2 \mathrm{~g})$ was dissolved in $8 \mathrm{~mL}$ of NMP by constant stirring and heating at $60^{\circ} \mathrm{C}$. The mixture kept under continuous stirring for $7 \mathrm{~h}$ to obtain a homogeneous solution. Resulting solution is cooled, and degassed in an ultrasonic bath to remove any bubbles. The resultant viscus PSf/NMP solution was casted to the form of a thin membrane using a glass plate and a doctor's blade via phase inversion technique. The solvent was allowed to evapourate for $30 \mathrm{~s}$ and it was immersed in coagulation bath containing distilled water for $24 \mathrm{~h}$, washed with distilled water followed by drying under vacuum [12].

\subsection{Synthesis of PSf/ZnO Blend Membranes}

Required quantity of PSf was dissolved in NMP under constant stirring at $60^{\circ} \mathrm{C}$. The solution is stirred constantly for $2 \mathrm{~h}$ to ensure the uniformity of the solution. A uniform solution of $\mathrm{ZnO}$-nanoparticles were prepared separately by dissolving pre weighed $\mathrm{ZnO}$ pwder in NMP under constant stirring and heating. Later both these solutions were mixed by keeping the temperature at $60^{\circ} \mathrm{C}$ and stirring at a constant rate for $7 \mathrm{~h}$ in order to obtain a homogeneous solution. The resultant solution is then sonicated and then casted on a glass plate using doctor's blade. The solvent was allowed to evapourate for $30 \mathrm{~s}$ and it was immersed in distilled water for $24 \mathrm{~h}$ followed by drying under vacuum. Table 1 shows the formulation of the PSf membranes.

Table 1 Dope formulation of PSf membranes

\begin{tabular}{ccc}
\hline Membranes & $\begin{array}{c}\text { ZnO } \\
\text { (g) }\end{array}$ & $\begin{array}{c}\text { PSf } \\
\text { (g) }\end{array}$ \\
\hline M1 & 0.0 & 1.0 \\
M2 & 0.02 & 0.98 \\
M3 & 0.04 & 0.96 \\
M4 & 0.06 & 0.94 \\
\hline
\end{tabular}

\subsection{Characterization of $\mathrm{PSf} / \mathrm{ZnO}$ blend membranes}

The morphology of the membranes was examined by using Scanning Electron Microscopy (SEM) analysis. FTIR of the membranes were also recorded to ensure the formation of the required type.

\subsection{Salt Rejection Studies}

All dried membranes were soaked in distilled water for $24 \mathrm{~h}$ before taking them for filtration performance analysis. Dead end filtration cell was used for performing filtration experiments. Filtration experiments were performed on $5 \mathrm{~cm}$ diameter circular membranes discs which provides total filtration area of about 


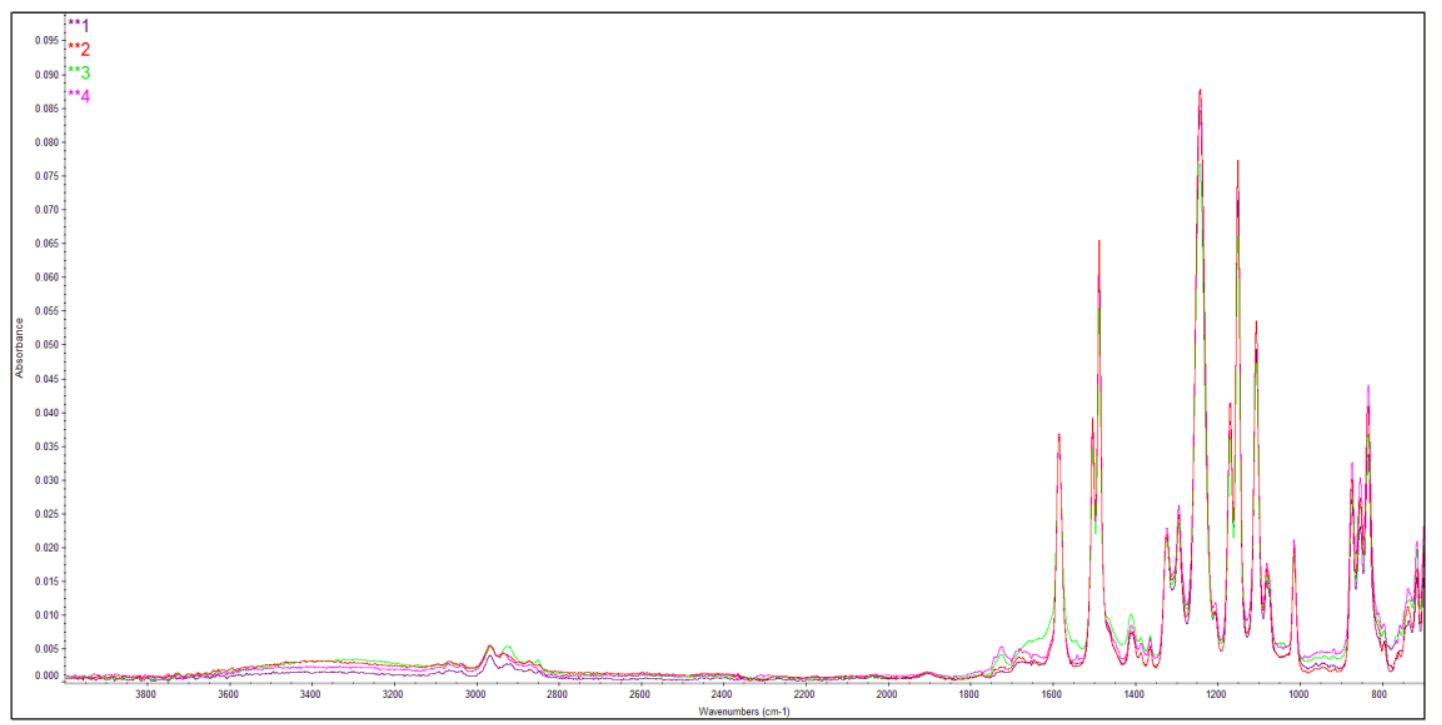

Figure 1 FTIR spectrums of pure PSf membrane, and at different loading of $\mathrm{ZnO}$ nano particles

$19.6 \mathrm{~cm}^{2}$. In order to give mechanical support to the membrane, these circular membrane samples were placed over porous stone support. The feed tank was filled with test solution and pressurized as per requirement.

The experimental setup was maintained at room temperature and constant stirring to minimize the effect of concentration polarization. Before taking any reading, permeate was allowed to attain equilibrium flow for atleast $15 \mathrm{~min}$. The concentration of feed and permeate solutions were measured using EQ-660A conductivity meter (Equip-tronics, India).

\subsection{RESULTS AND DISCUSSION}

\subsection{Fourier Transform Infrared Spectroscopy (FTIR)}

The chemical structures of the $\mathrm{PSf} / \mathrm{ZnO}$ blend membranes were characterized by FTIR, and its infrared spectrum was compared to that of a pure PSf membrane in Figure 1.

\subsection{Scanning Electron Microscopy (SEM)}

Figure 2 presents the SEM images of the membranes embedded with different mass fractions of $\mathrm{ZnO}-\mathrm{PSf}$. The increased composition of $\mathrm{ZnO}$ in casting solution resulted in a highly porous membrane structure. Highly porous and hydrophilic nature of $\mathrm{PSf} / \mathrm{ZnO}$ membranes contributed to the enhanced flux. Figure 3 shows the succesfull incorporation of $\mathrm{ZnO}$ in the PSf membrane matrix.

\subsection{Salt Rejection Performance}

Figure 4 shows the salt rejection results of synthesized membranes against $\mathrm{NaCl}$. Performance of the membrane increases as the weight percentage of the $\mathrm{ZnO}$ nanoparticles increases. $\mathrm{ZnO}$ nano particles makes the membrane more hydrophilic which is accounted for the increased performance. 


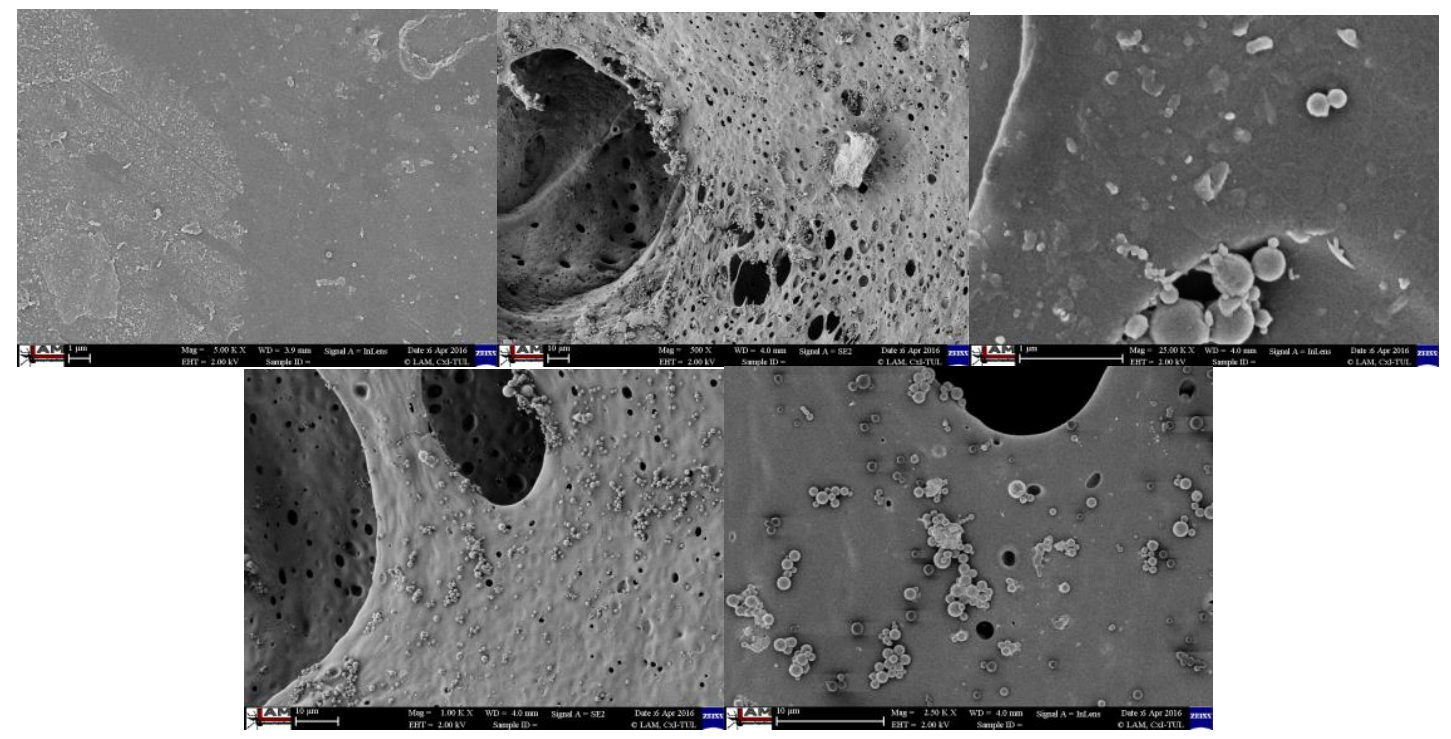

Figure 2 SEM images of top surface of the membranes M-1 (top left), M-2 (top middle and right) and M-3(bottom left and right)

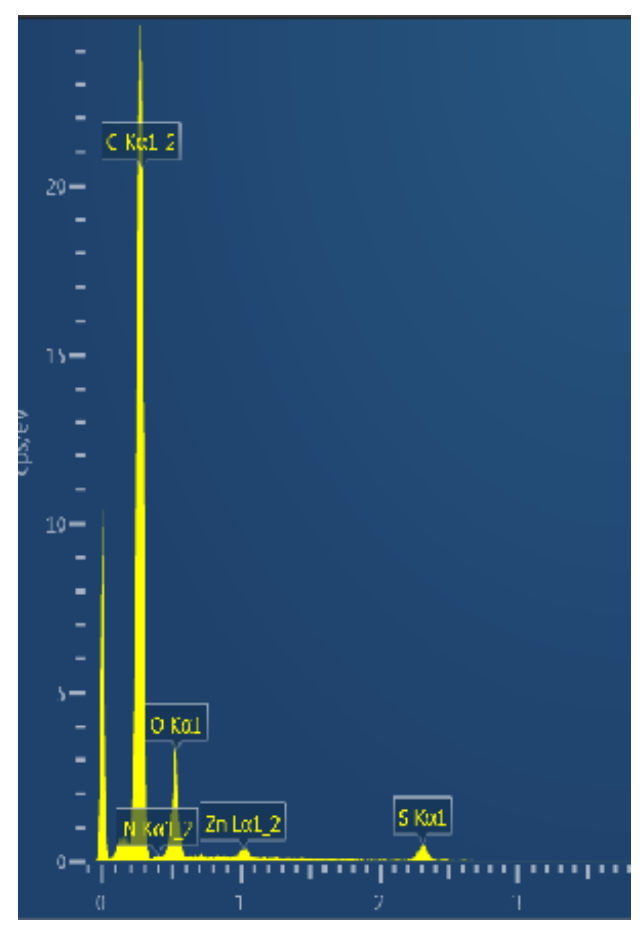

Figure 3 EDX analysis PSf-ZnO blend membrane M2

\subsection{Water Uptake of the Membrane}

In order to understand the water uptake properties, dry membranes were cut into pieces of abour 2 sizes, dry weight was noted and then these samples were immersed in distillaed water for $24 \mathrm{~h}$. After than, the membrane were taken out of water and surface water was removed using blotting paper, after which the wet membrane weight was noted. The percent water uptake was calculated using equation,

Water uptake $(\%)=\frac{W_{w}-W_{d}}{W_{w}} * 100$

where $\mathrm{w}_{\mathrm{w}}$ and $\mathrm{w}_{\mathrm{d}}$ are the weight $(\mathrm{g})$ of wet and dry membranes respectively.

The results are presented in Figure 5. It can be noticed that, uppermost water uptake observed was $81 \%$ and the minimum was $45 \%$. The membrane with highest percentage of $\mathrm{ZnO}$ exhibited maximum water uptake which provides an evidence for the fact that, the increase in the percentage of $\mathrm{ZnO}$ nano particles enhances the hydrophilic nature of the membrane. 


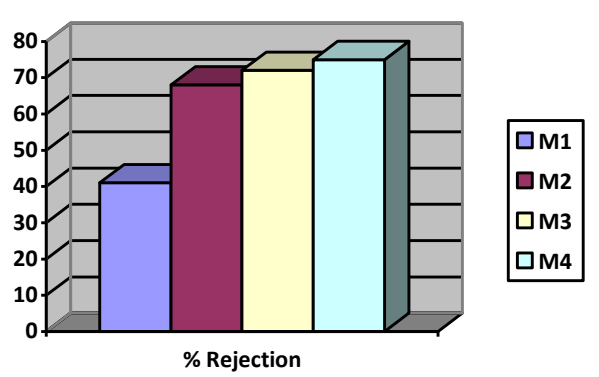

Figure 4 The $\mathrm{NaCl}$ electrolyte rejection study of membranes at 2 bar pressure

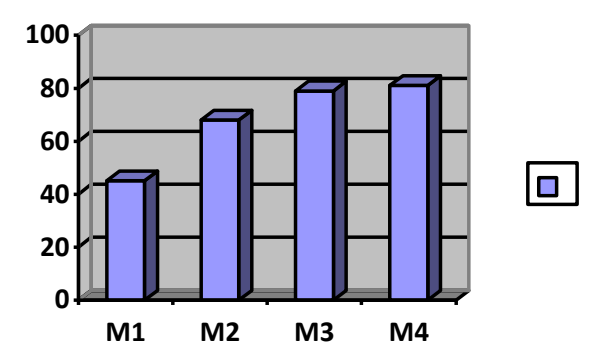

Figure 5 Water uptake of the membranes

\subsection{CONCLUSION}

In summary, PSf-ZnO blend membranes were synthesized by phase inversion method by mixing PSf and $\mathrm{ZnO}$ with NMP at $60^{\circ} \mathrm{C}$. Depending on the amount of $\mathrm{ZnO}$ added, the resultant membranes achieve different removal efficiency against $\mathrm{NaCl}$.

\section{ACKNOWLEDGEMENT}

The authors would like to thank Dr. Vinod V.T.P for his help in recording the IR and SEM of the membranes. Authors are also thankful to Principal and management of Payyanur College for providing facilities to finish this work.

\section{REFERENCES}

[1] M. Padaki, A. M. Isloor, P. Wanichapichart, A. F. Ismail.
2012. Preparation and Characterization of Sulfonated Polysulfone and N-phthloyl Chitosanblend Composite Cation-exchange Membrane For Desalination. 298: 42-48.

[2] S. S. Shenvi, A. M. Isloor, A. F. Ismail. 2015. A Review on RO Membrane Technology: Developments and Challenges. Desalination. 368: 10-26.

[3] J. Miao, G. Chen, C. Gao, C. Lin, D. Wang, M. Sun. 2006. Preparation and Characterization of N, O Carboxymethylchitosan (NOCC)/polysulfone

Composite Nano Filtration Membranes. J. Membr. Sci. 280: 478-484.

[4] M. Padaki, A. M. Isloor, P. Wanichapichart. 2011. Polysulfone/N-phthloyl Chitosan Novel Composite Membranes for Salt Rejection Application. Desalination. 279: 409-414.

[5] A. K. Nair, A. M. Isloor, R. Kumar, A. F. Ismail. 2013. Antifouling and Performance Enhancement of Polysulfone Ultrafiltration Membranes Using $\mathrm{CaCO}_{3} \quad$ Nanoparticles. Desalination. 322: 69-75.

[6] X. Zhang, Y. Wang, Y. You, H. Meng, J. Zhang, X. Xu,. 2012. Preparation, Performance and Adsorption Activity of $\mathrm{TiO} 2$ Nanoparticles Entrapped PVDF Hybrid Membranes. Appl. Surf. Sci. 263: 660-665.

[7] L. Yu, Z. Xu, H. Shen, H. Yang. 2009. Preparation and Characterization of PVDF-SiO2 Composite Hollow Fiber UF Membrane by Sol-gel Method. J. Membr. Sci. 337: 257-265.

[8] N. A. A. Hamid, A. F. Ismail, T. Matsuura, A. W. Zularisam, W. J. Lau, E. Yuliwati, M. S. Abdullah. 2011. Morphological and Separation Performance 
Study of Polysulfone/Titanium Dioxide (PSF/TiO2) Ultrafiltration Membranes for humic Acid Removal. Desalination. 273: 85-92.

[9] C. Hegde, A. M. Isloor, M. Padaki, P. Wanichapichart, Y. Liangdeng. 2011. Synthesis and Desalination Performance of Ar+-N+ Irradiated Polysulfone Based New NF Membrane. Desalination. 265: 153-158.

[10] B. M. Ganesh, A. M. Isloor, M. Padaki. 2012. Preparation and Characterization of Polysulfone Andmodified Poly IsobutyleneAlt-maleic Anhydride Blend NFmembrane. Desalination. 287: 103-108.
[11] X. Li, S. D. Feyter, I. F. J. Vankelecom. 2008. Poly(sulfone)/sulfonated Poly (Ether Ether Ketone) Blend Membranes: Morphology Study and Application in the Filtration of Alcohol Based Feeds. $J$. Membr. Sci. 324: 67-75.

[12] R. Kumar, A. M. Isloor, A. F. Ismail. 2014. Preparation and Evaluation of Heavy Metal Rejection Properties of Polysulfone/Chitosan, PolySulfone /N-Succinyl Chitosan and Polysulfone/N-Propyl Phosphonyl Chitosan Blend Ultrafiltration Membranes. Desalination. 350: 102-108. 